\title{
LEGUMINOSAS CAESALPINIOIDEAE E MIMOSOIDEAE NATIVAS DO RS, COM VALOR FORRAGEIRO - UMA REVISĀO
}

Jumaida M. Rosito

Departamento de Biologia. Centro de Ciencias Naturais e Exatas.UFSM. Santa Maria, RS.

Luîs R.M. Batista

Departamento de Botānica. Universidade Federal do Rio Grande do Sul. Porto Alegre, RS.

RESUMO

O presente trabalho objetivou a obtenção do maior número possivel de informaçōes sobre as espécies de Caesalpinioideae e Mimo soideae nativas do RS, com valor forrageiro. Nove espécies foram clas sificadas desta maneira: Caesalpinia epunctata (Vog.) Benth., Cas sia patellamia DC., Cassia pilifera Vog., Cassia repens Vog., Cassia rotundifolia Pers., Desmanthus depressus Humb. \& Bonpl. ex Willd., Mimosa dutrae Malme, Mimosa flagelzaris Benth., Prosopis a'-garobilza Griseb. Com exceção de $C$. rotundifolia, de porte herbáceo e $P$. alga robizza, de porte arbōreo, as demais espēcies podem ser caracteriza das como arbustivas, de altura variāvel, podendo atingir $1 \mathrm{~m}$. A maior parte das espécies são perenes, embora Cassia patezzaria pos sa apresentar comportamento de planta anual, em alguns casos. De acordo com as observações obtidas, as espécies apresentam um desen volvimento estival e podem ser encontradas, de uma forma geral, em campos secos. Com relação ao interesse forrageiro, C. epunctata, $C$. repens, $D$. depressus e $M$. flagelzaris são consideradas forrageiras regulares ao passo que $C$. pilifera e $C$. patellaria são tidas como pobres neste aspecto. C. rotundifolia apresenta forragem macia bem aceita pelo gado em várias regiões do país, o mesmo não ocorrendo no sul, onde até mesmo tentativas para sua cultura fracassaram. $P$. $a \underline{Z}$ garobizza, embora limitada a uma área pequena do Estado, parece ser uma espécie com um bom potencial.

\section{SUMMARY}

ROSITO, J.M. and BATISTA, L.R.M. Native caesalpinioideae and Mimo soideae species of RS, Brazil, with foraging valve - A Review. Ciência e Natura, 7: 163 - 180 .

This work aimed at gathering information about native Cae salpinioideae and Mimosoideae species with foraging value. Niriespecies were classified as, Caesalpinia epunctata (Vog.) Benth., Cassia pa tellaria DC., Cassia pilifera Vogh., Cassis repens Vog., Cassis ro tundifolia Pers., Desmanthus depressus Humb. \& Bonpl. ex Willd., Mi mosa dutrae Malme., Mimosa flagelzaris Benth., Prosopis Algarobizza 
Griseb. Except $C$. rotundifolia, herbaceous, and $P$. algarobizla,weady, the other species are perennials altough $C$. patezzaria may behave as annual in some cases. According to the data obtained, the species present summer growth and are generally found in dry fields.

Regarding the potential forage value; Caesalpinia epuncta ta, Cassia repens, Desmanthus depressus and Mimosa flagelzaris are considered as regular forages while Cassia pilifera and Cassia pa tezzaria are poor forages. Cassia rotundifolia presents a soft forage well accepted by catlle in several regions of the country but not in the South where even cultivation trials failed. Prosopis algarobilza, altough restricted to a small area of the State, seems to be a spe cies with good potential as a forage.

INTRODUÇAO

Quando são conduzidos experimentos em pastagens nativas, torna-se indispensāvel o conhecimento prēvio das espēcies formado ras destas pastagens, alēm da obtenção de informações pertinentes à quantidade e qualidade destes componentes. No que diz respeito às le guminosas forrageiras, as FABOIDEAE, dada sua importāncia e ao bom nūmero de espēcies ūteis na alimentação dos nossos rebanhos, têm si do objeto de diversos estudos, tanto na área taxonômica, quanto na de utilização. Podem ser citadas como exemplo: Desmodium canum DC., diversas espēcies do gênero stylosanthes, que vêm despertando gran de interesse como recurso forrageiro, Desmodium adscendens (Sw.) DC., e Trifolium riograndense Burkart, que vem sendo objeto de estudos citogenēticos e de avaliação agronōmica, com vistas ao seu melhora mento como espēcie forrageira. O mesmo interesse parece não se apli car às MIMOSOIDEAE e CAESALPINIOIDEAE que, embora' não apresentem, de uma maneira geral, um elevado valor como forragem, podem ser cons $\underline{i}$ deradas como um recurso potencial a ser desenvolvido e aproveitado, o que justificaria, por si sō, uma maior atenção ao estudo de suas espēcies. Deve-se salientar, ainda, que algumas espēcies pertencen tes a estas subfamīilias, embora sejam pouco conhecidas no Estado, são utilizadas com sucesso na alimentação de rebanhos em outros paĩ ses e atē mesmo em outras regiões do Brasil (BURKART, 1952;PIMENTEL GOMES, 1975). Estas idéias são reforçadas pelo fato de que a pesqui sa agronōmica na ārea de pastagens, tem se voltado à valorização dos nossos recursos naturais, desenvolvendo tēcnicas e sistemas de avaliação compatĩveis com as caracteristicas de nossas pastagens, objetivando, desta forma, encarar os campos naturais como uma alter nativa viāvel e oportuna em termos de produção animal.

0 objetivo principal do trabalho, foi a coleta de informa ções acerca das espécies nativas de CAESALPINIOIDEAE e MIMOSOIDEAE, com interesse forrageiro, a fim de estimular um maior conhecimento 
das mesmas e de fornecer opções para o uso de leguminosas nas pasta gens nativas do Estado.

\section{MATERIAL E METODOS}

A lista inicial de espécies forrageiras, a partir da qual este estudo foi elaborado, foi extraida de um trabalho de BARRETO e KAPPEL (1969), referente às espēcies de gramīneas e leguminosas das pastagens do RS, classificadas em forrageiras pobres, regulares, boas, ótimas e rejeitadas pelos animais. A esta lista foram acrescidas ou tras espécies, depois da consulta às obras de BURKART (1952), ROCHA (1971) e ALCĀNTARA e BUFARAH (1979), referentes às leguminosas. Re sultaram, assim, cinco espēcies de CAESALPINIOIDEAE e quatro de MI MOSOIDEAE, a saber: Caesalpinia epunctata (Vog.) Benth., Cassia pa tellaria DC., Cassia pilifera Vog., Cassia repens Vog., Cassia ro tundifolia Pers., Desmanthus depressus Humb. \& Bonpl. ex Willd., Mi mosa dutrae Malme., Mimosa flagelzaris Benth. e Prosopis algarobizla Griseb.

Os trabalhos consultados para a realização desta revisão foram encontrados nas Bibliotecas do Departamento de Botānica(UFRGS), Secretaria de Agricultura do RS, Fundação Zoobotânica (RS), Faculda de de Agronomia (UFRGS), Faculdade de Veterināria (UFRGS), Institu to de Biociências e Biblioteca Central da UFRGS. Alguns trabalhos fo ram ainda solicitados a Instituições de fora do Estado. Para as ilus trações, foi utilizado material de herbārio (ICN-Herbārio do Depar tamento de Botânica do Instituto de Biociências da UFRGS, Porto Ale gre-RS e PACA-Herbārio da Universidade Vale do Rio dos Sinos, São Leopoldo, RS), além de material fresco, quando possível. A descrição de cada espēcie foi baseada em informações contidas nos trabalhos de ARAUJO (1942), BURKART (1952), CABRERA (1953 e 1965), PARADI(1959); ALCÃNTARA e BUFARAH (1979), em observações das excicatas e de mate rial fresco e algumas comunicações pessoais. Para algumas espécies, devido à ausência quase total de informações no referente a sua ut lização econômica, foi possivvel reunir apenas dados relacionados à caracterização botânica, alēm de.sua citação como espécie forragei ra.

Considerando o enfoque do trabalho, ligado principalmente à importāncia forrageira das espēcies, as descrições fornecidas são de carāter geral, objetivando um reconhecimento rāpido das mesmas.

\section{RESULTADOS E DISCUSSÃO}

As CAESALPINIOIDEAE são plantas de hābito muito variado, podendo ser herbāceas, sub-arbustivas, arbustivas ou arbōreas. As folhas, compostas, são pinadas, bipinadas ou, mais raramente, sim ples. As flores são vistosas, pentāmeras, diclamĩdias (raramente 
monoclamỉdeas), hermafroditas, com simetria bilateral ou, poucas ve zes, radial. As pētalas são livres e o cālice geralmente dialissēpa 10. Os estames, em número de 3 a 12 , chegam a mesma altura da coro la ou podem ser superados por ela. As espécies desta sub-famîlia a presentam pré-floração imbricada ascendente, e a pétala superior, interna, é coberta nos bordos pelas outras pētalas.

ESPECIES CONSIDERADAS: Caesalpinia epunctata (Vog.)Benth., Cassia patelzaria DC., Cassia pilifera Vog., Cassia repens Vog., Cassia rotundifolia Pers.

1. Caesalpinia epunctata (Vog.) Benth.

Esta espécie é caracterizada por individuos de porte ar bustivo, de pouca altura, com ramos prostrados e ascendentes ou ere tos. São plantas perenes e apresentam um desenvolvimento estival. As folhas, multijugas e bipenadas, são formadas por folíolos sem glândulas e com nervuras muito visiveis em ambas as faces. 0 legume apresenta-se arqueado, coberto de pêlos pequenos e plumosos, quando maduros.

C. epunctata pode ser encontrada em campos sujos, secos, com solo arenoso, sendo distribuida pela metade sul do Estado e nor deste da costa (RAMBO, 1966).

BARRETO e KAPPEL (1969), classificaram-na como uma forra geira regular. Não foram encontrados outros registros desta espēcie com respeito a sua utilização econômica e ao seu comportamento nas pastagens naturais.

2. Cassia patelzaria DC.

São ervas anuais, perenes, de porte ereto com caules rami ficados e pilosos, podendo atingir $1 \mathrm{~m}$ de altura, aproximadamente. Seu desenvolvimento é estival. As folhas alternas e compostas, com 4 a $7 \mathrm{~cm}$ de comprimento, são formadas por 10 a 12 pares de folíolos oblongo-lanceolados. As flores, amarelas, são pequenas e reunidas em grupos de 2 ou 3 . Os frutos, vagens 1 ineares, achatadas e pilo sas, medem 3 a $4 \mathrm{~cm}$ de comprimento por 3 a $4 \mathrm{~mm}$ de largura, aprox $\underline{i}$ madamente (Figura 1).

Esta espécie, de acordo com RAMBO (1966), pode ser encon trada em lugares secos e abertos, sendo que sua distribuição é atra vēs de toda a ārea de campo do Estado, exceto no planalto nordeste.

BARRETO e KAPPEL (1969), classificaram C. patelzaria como forrageira pobre. ARAUJO (1942), faz referēncia ao cultivo desta es pécie em Tupanciretã (RS), hā aļ̣uns anos, com sementes trazidas de Minas Gerais. Segundo o autor, a espēcie demonstrou muito boa resis tência às condições do meio, no primeiro ano, produzindo boa quanti dade de matēria verde e frutificando bem antes do inverno. Contudo, depois de dois anos, foi atacada por uma moléstia desconhecida que 

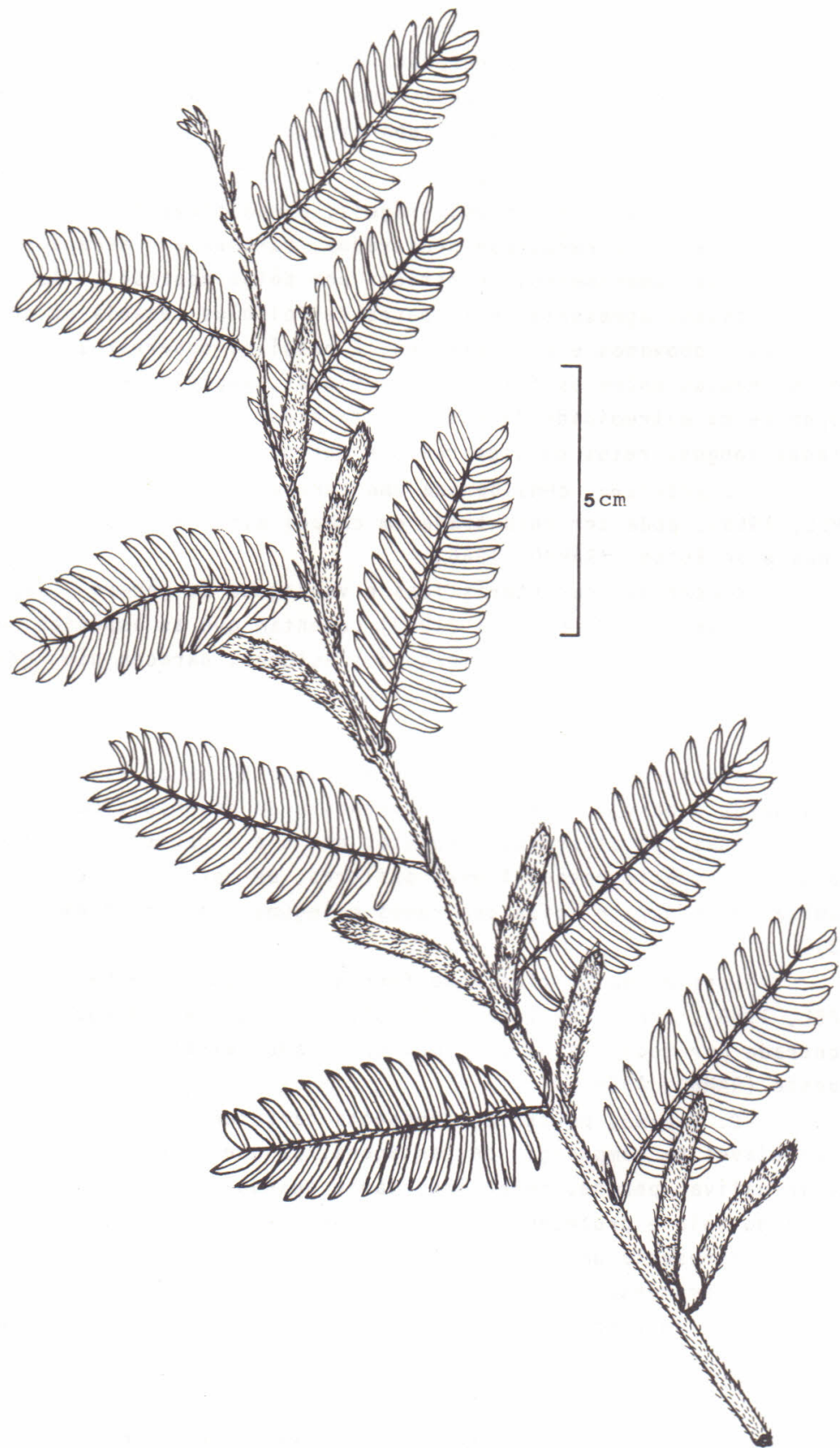

Figura 1 - Cassia patellaria DC.: Detalhe do häbito. 
aniquilou a cultura e os individuos que nasceram nos anos seguintes. Não foram encontradas outras referēncias sobre a utilização desta le guminosa nem comentārios adicionais que pudessem justificar o fra casso da tentativa de cultivo em Tupanciretã.

3. Cassia pilifera Vog.

São arbustos pequenos, frágeis, abundantemente ramifica dos desde a base. Os ramos são prostrados, raramente ascendentes, de até $5 \mathrm{~cm}$ de comprimento, revestidos por pêlos esparsos. As fo Thas, compostas, apresentam dois pares de foliolos sésseis ou curto -peciolados, obovados e assimétricos. E possível observar a presen ça de glândulas entre os folíolos. As flores, amarelas e grandes, agrupam-se na extremidade de ramos. Esta espécie apresenta legumes bastante longos, retos ou ligeiramente curvos (Figura 2).

C. pilifera, considerada uma forrageira pobre (BARRETO e KAPPEL, 1969), pode ser encontrada em campos altos e secos do cen tro-oeste do Estado (RAMBO, 1966).

Apesar das características e vantagens do gênero Cassia, descritas acima, ROCHA et alii (1979) comentam que as espécies des te gênero nodulam mal e, na opinião dos autores, parecem não ofere cer grandes possibilidades forrageiras.

\section{Cassia repens Vog. (Cássia rasteira)}

Arbustos pequenos, podendo alcançar $50 \mathrm{~cm}$ de altura, rami ficada desde a base, rizomatosas, perenes e de desenvolvimento esti val. As folhas são alternas, compostas por 6 a 8 pares de foliolos pequenos. A espécie possui flores axilares, de corola amarela, dis tribuídas mais para o ápice dos ramos e legumes indeiscentes (Figu ra 3 ).

Esta espécie, tida como forrageira regular (BARRETO e KAPPEL, 1969), cresce em lugares secos, arenosos ou pedregosos e $\bar{e}$ encontrada por toda a área de campo do Estado, exceto no planalto nordeste (RAMBO, 1966).

C. repens, portanto, apresenta caracteristicas que a tor nam desejāvel na composição de pastagens, jā que, além de ser uma espécie nativa, perene, fator importante quando se considera a co bertura do solo e proteção de outras espécies em periodos desfavorá veis, ela apresenta um hábito prostrado e rizomatoso. Estas qualida des são extremamente desejāveis, quando se objetiva a persistência de individuos em campos submetidos a pastejo e onde exista a compe tição entre espēcies.

5. Cassia rotundifolia Pers.

São perenes, de porte herbāceo, ramoficadas desde a base, geralmente rasteiras, medindo aproximadamente $10 \mathrm{~cm}$ de altura. As 


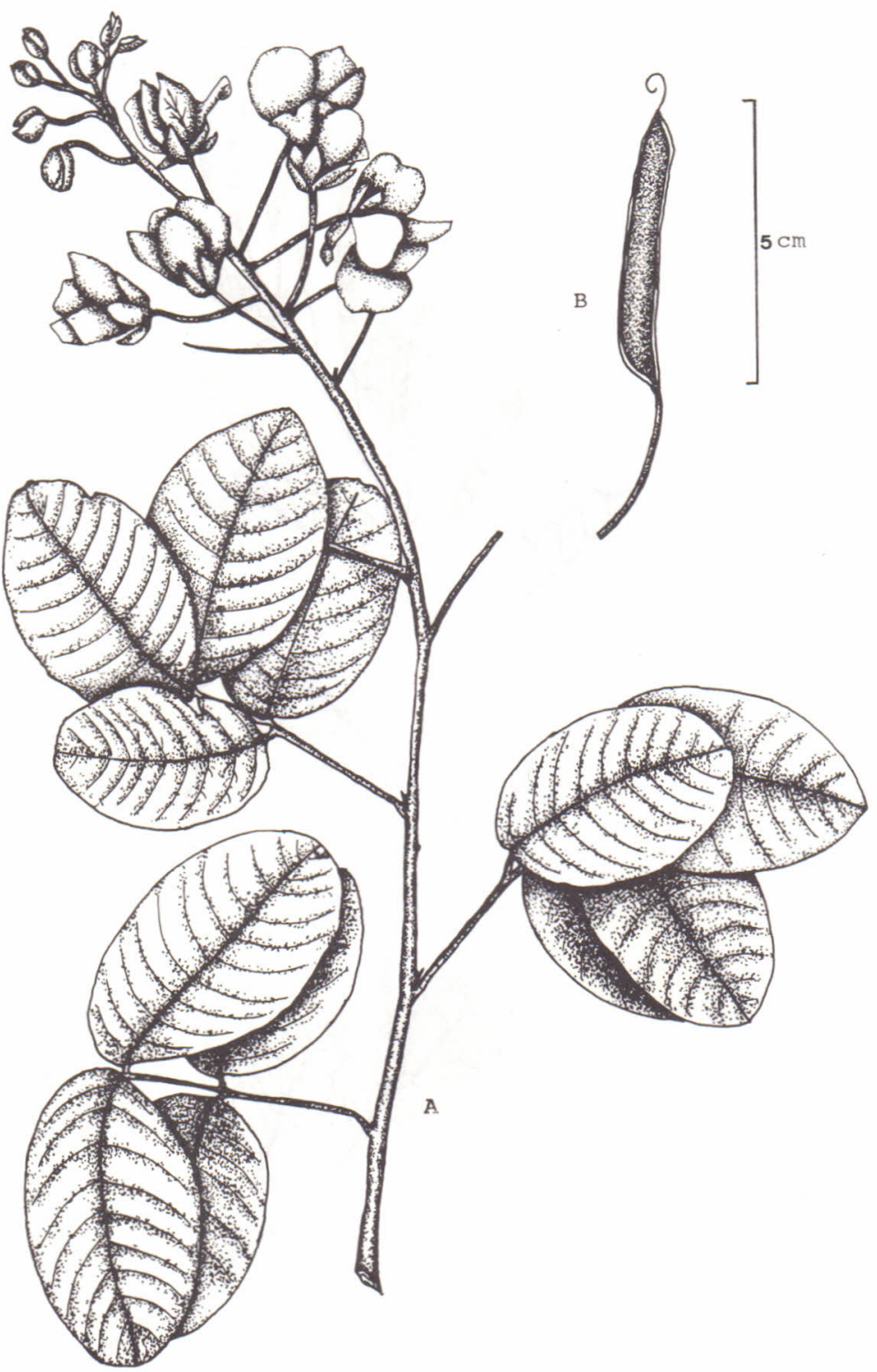

Figura 2 - Cassia pilifera Vog.: a) Detalhe do häbito b) Fruto

folhas alternas, pecioladas, são compostas por dois foliolos muito variáveis quanto à forma e dimensões, sendo em geral obtusos e as simétricos. As estîpulas têm a forma lanceolado-cordiformes. Esta 


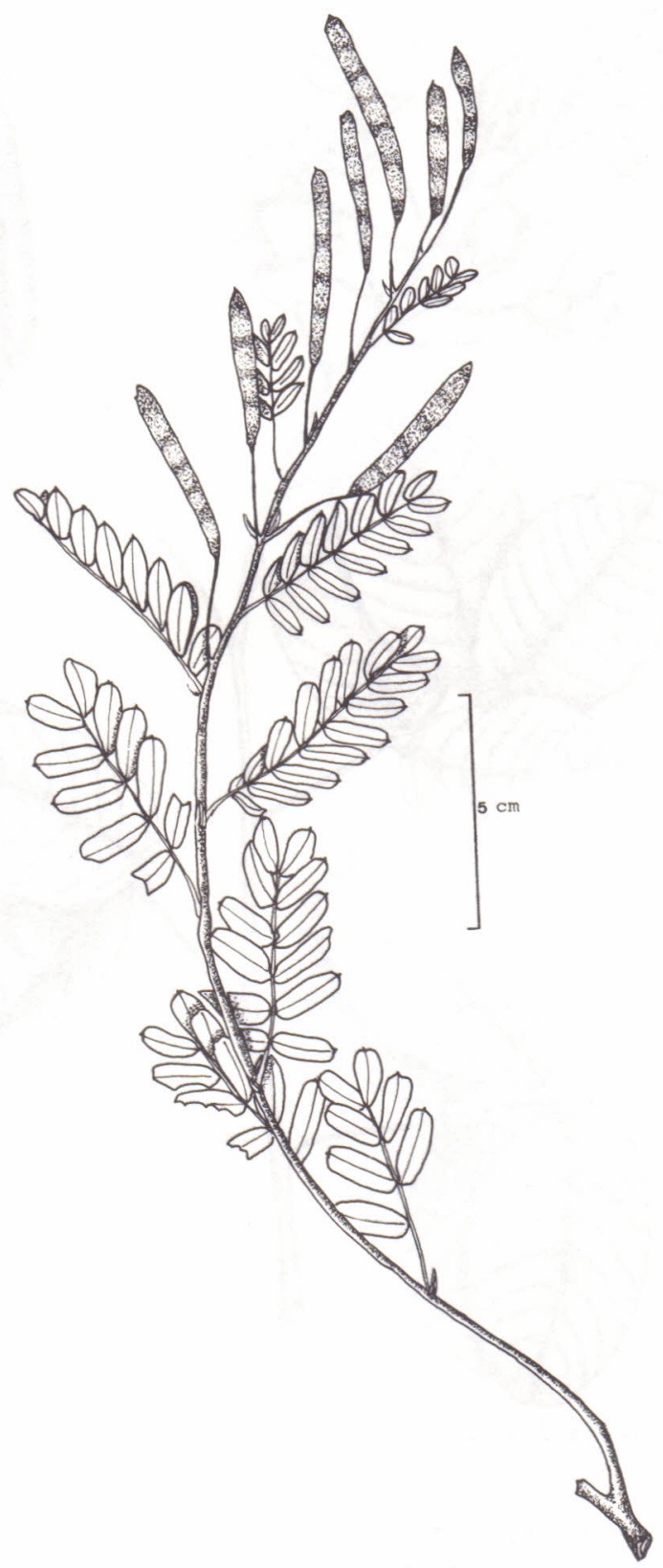

Figura 3 - Cassia repens Vog. Detalhe do hābito. 
espécie apresenta flores de corola amarelo-pálido, solitārias, axị lares e legumes achatados lineares de 2,5 a $5 \mathrm{~cm}$ de comprimento, con tendo 10 sementes, em média (Figura 4 ).

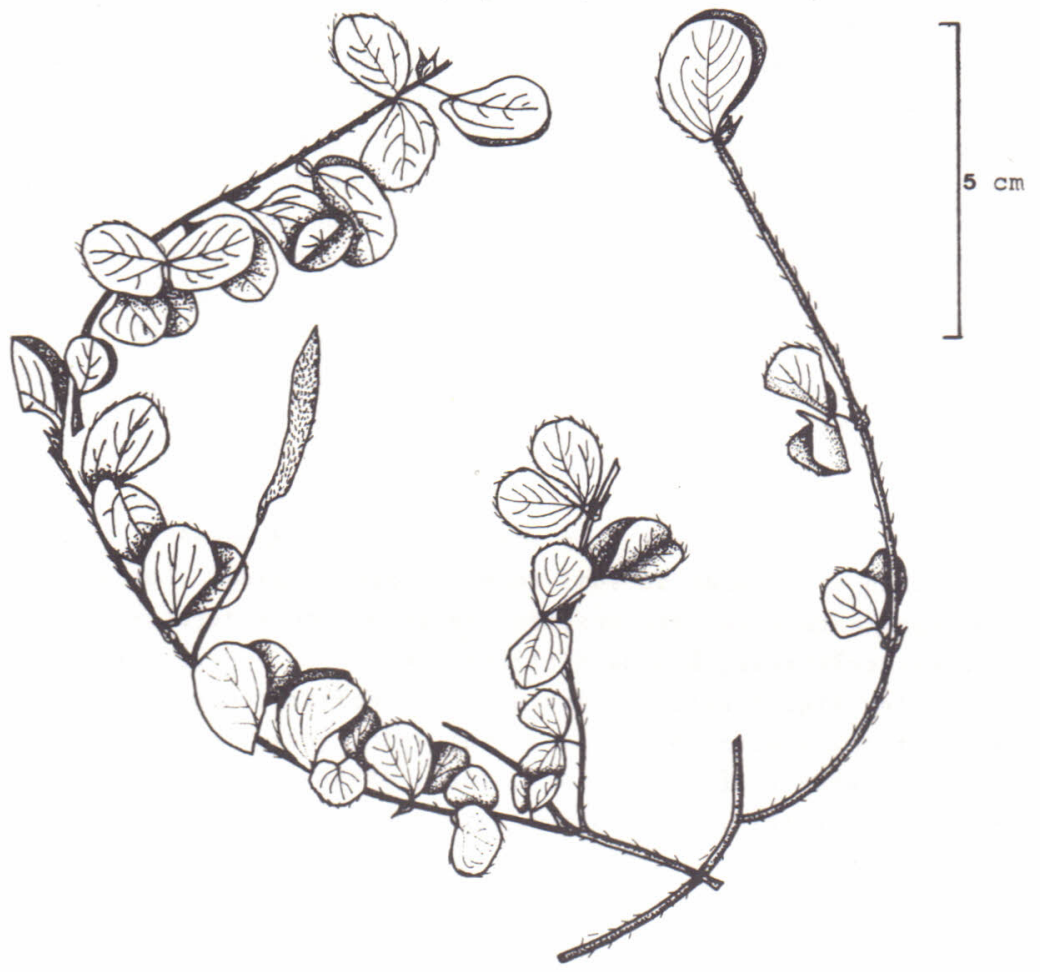

Figura 4 - rotundifolia Pers.: Detalhe do häbito.

C. rotundifolia pode ser encontrada em campos secos, dis tribuindo-se, no RS, pelas regiões planas do sudoeste (RAMB0, 1966).

De acordo com ARAUJO (1942), esta espēcie fornece forragem macia e bem aceita pelo gado. Contudo, o autor salienta que, apesar de suas boas qualidades, no sul, esta espécie è recusada pelo gado, e que tentativas para sua cultura fracassaram.

Na sub-famīlia MIMOSOIDEAE, estão incluĩdas espēcies de hābito sub-arbustivo ou arbōreo, com folhas bipinadas ou, mais rara mente, pinadas. As flores, diclamideas, apresentam simetria radial e estão, geralmente, reunidas em espigas, capítulos ou racemos espi ciformes. A corola é gamopétala (4 a 5 pétalas), pequena, sendo o cálice gamossépalo, na maioria das vezes. Os estames (4 ou mais), co mumente ultrapassam a corola.

ESPECIES CONSIDERADAS: Desmanthus depressus Humb. \& Bonpl. Willd., Mimosa dutrae., Mimosa flagellaris Benth., Prosopis algarobilla Griseb. 
1. Desmanthus depressus Humb. \& Bonpl. ex Willd.

Com relação ao gênero Desmanthus, para existir uma enorme escassez de coletas e dados bibliogrāficos, embora algumas espēcies sejam bastante frequentes em nossos campos. Além disso, pelo aspec to vegetativo, é possível que este gênero venha a ter algum interes se econômico na opinião de ROCHA et alii (1979).

os individuos de $D$. depressus, caracterizam-se por ser ar bustos pequenos, abundantemente ramificados desde a base, com ramos cilîndricos e delgados. São plantas perenes, de desenvolvimento es tival, apresentando raizes napiformes (xilopōdios). As folhas alter nadas, bipinadas ( 1 a 5 pinas), apresentam pīnulas (em nūmero de 10 a 20) com uma glândula prōxima à inserção do par inferior. As flo res, em capitulos globosos, possuem corola amarelo-esbranquiçado, sendo os legumes deiscentes, lineares, retos ou falcados, de 4 a 5 $\mathrm{cm}$ de comprimento, aproximadamente (Figura 5).

Quanto a sua utilização, BARRETO e KAPPEL (1969), conside ram esta espécie uma forrageira regular, embora MANGANARO (1919) ad virta quanto à toxidade de suas sementes para o gado. Contudo, um ponto importante a ser esclarecido, antes das considerações sobre suas características, é o da distinção entre $D$. depressus e $D$. vir gatus Willd. Alguns autores parecem não precisar com exatidão onde começa e termina outra espēcie, acreditando, inclusive, em varieda des de uma mesma espécie (BENTHAM, 1881; MANGANARO, 1919). Mais re centemente, BURKART (1939) argumenta que, jā que as espēcies são re ciprocamente afins, $\bar{e}$ possível que tenham se hibridizado. De acordo com ALCĀNTARA e BUFARAH (1979), alguns botānicos de renome conside ram $D$. depressus e $D$. virgatus tão pröximas, que podem ser facilmen te reunidas e consideradas uma sō espécie: D. virgatus.

A diferenciação vegetativa mais evidente entre as duas es pēcies, ē o hábito mais prostrado e a menor ramificação de $D$. dé pressus, que não ultrapassa aos $40 \mathrm{~cm}$ de altura (BURKART, 1979). D. virgatus (L.) Willd., pode ser descrito como um arbusto pouco ramo so, glabro, ereto, de 0,30-1,5 m de altura. Esta espécie possui nü merosas sementes ovais, com manchas grisāceas vesiculosas. De acor do com BURKART (1979), D. virgatus floresce na primavera, frutifica de fevereiro a março, e é encontrada em campos sujos, roças abando nadas ou solos alterados.

Frequentemente as duas espēcies ocorrem juntas, e RAMBO (1966) mencionado apenas D. depressus, comenta sua distribuição pe la metade sul do Estado em solos secos. Contudo, ALCANTARA e BUFARAH (1979), fazendo referência à espēcie, descrevem-na como vegetando em solos arenosos e argilosos, porém relativamente ümidos, sem ser en charcados, com fertilidade mëdia ou boa, podendo adaptar-se tambēm às chuvas prolongadas. Os autores acreditam que uma adubação causaria 


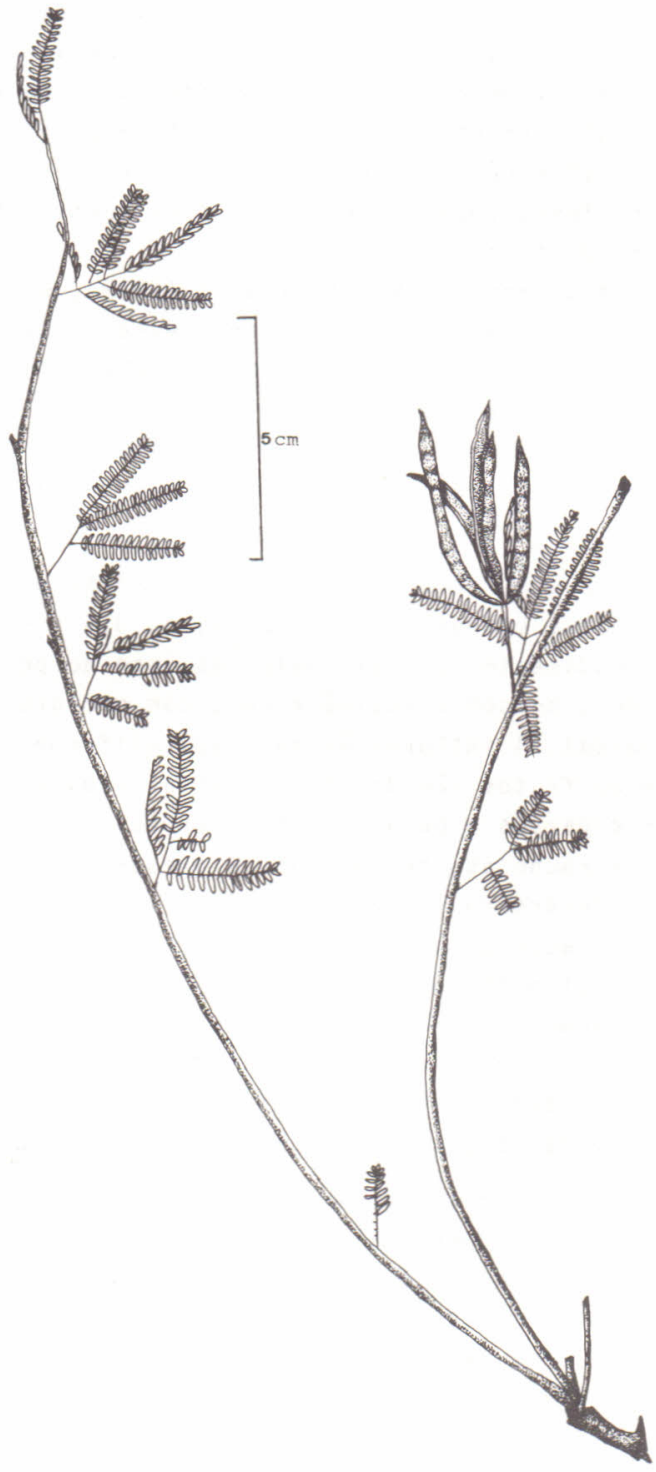

Figura 5 - Desmanthus depressus Humb. \& Bonpl. ex Willd.: Detalhes do häbito. 
um aumento considerāvel na produção. A espēcie demonstra rusticida de, pois resiste também a períodos de seca, devido, provavelmente, à presença dos xilopōdios.

Quanto à aceitabilidade pelo gado, parece ser boa, podendo ser associada com gramineas rasteiras e agressivas. A propagação se dá por sementes, produzidas em quantidades razoavelmente altas, com alto valor de germinação, que é facilitada pela escarificação.

Esta espécie apresenta teores de proteina que variam de 10 a 18\% no feno, podendo ser usada para corte sob pastejo, adubação e cobertura do solo.

De acordo com ROCHA et alii (1979), a presença de acūleos muito desenvolvidos diminuiria o interesse forrageiro de algumas es pécies de Mimosa, embora ALCANTARA e BUFARAH (1979) frisem que a maioria das espēcies deste gênero, forrageiras, possuem ramos flexí veis com folhas macias e que as värias espécies inermes, dotadas de massa verde abundante, têm sido muito evidenciadas.

\section{Mimosa dutrae Malme (Juquiri)}

Arbustos pequenos, de häbito prostrado, com caules estolo níferos, folhas compostas, bipinadas, de 3,5 a $6,5 \mathrm{~cm}$ de comprimen to, aproximadamente, sem glāndulas na base do peciolo. Os foliolos são pequenos, agudos e assimētricos, com nervura mediana acentuada na face dorsal. A inflorescēncia, capituliforme, possui um longo pe dūnculo e os frutos são do tipo lomento. Toda a planta $\bar{e}$ coberta por pêlos esparsos e pequenos. Esta espêcie è característica de cam pos secos e rochosos, heliōfilas, florescendo entre novembro e de zembro até fevereiro (BURKART, 1979) (Figura 6).

De acordo com RAMBO (1966), M. dutrae pode ser encontrada na borda do planalto nordeste do Estado.

Segundo BURKART (1979), no RS existe uma forma gigante com medidas maiores que o normal observado, embora apresente caracteres qualitativos idênticos à forma tîpica. Enquanto a inflorescência a cança $1,5 \mathrm{~cm}$ de comprimento, a forma gigante pode atingir $3 \mathrm{~cm}$.

3. Mimosa fiagezzaris Benth.

Arbustos perenes, de desenvolvimento estival, com ramos atingindo atē $50 \mathrm{~cm}$ de altura. As folhas são compostas, bipinadas, de 3,5 a $8,5 \mathrm{~cm}$ de comprimento, aproximadamente, com pínulas assimé tricas. As flores estão reunidas em capĩtulos com pedūnculos bastan te longos (Figura 7).

Esta espēcie pode ser encontrada em campos secos, de vege tação rasteira ou arbustiva e, no RS, distribui-se por toda a ārea de campo, com exceção do planalto médio (RAMBo, 1966).

De acordo com BARRETO e KAPPEL (1969), M. flagezzaris po de ser considerada uma forrageira regular. 


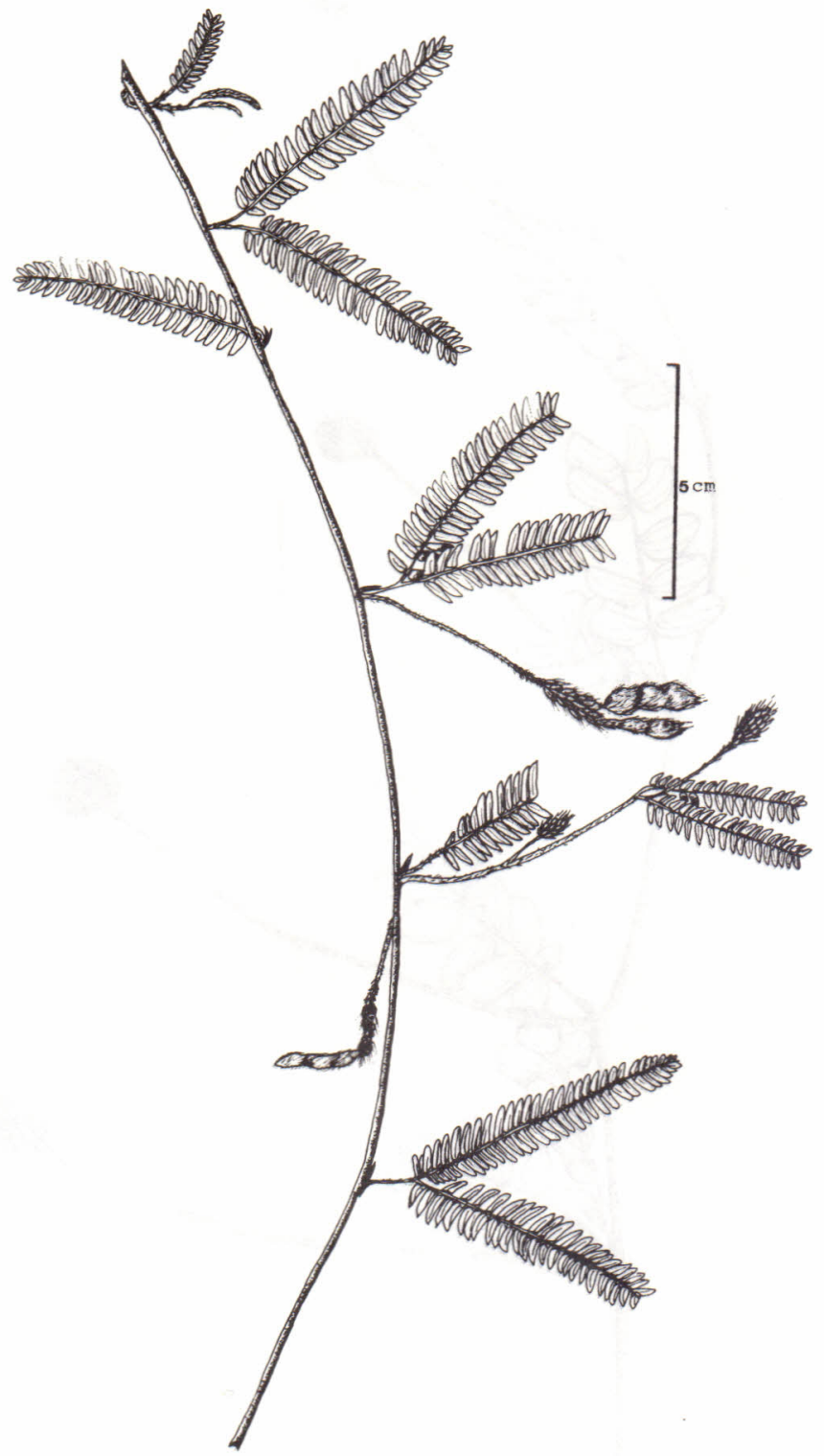

Figura 6 - Mimosa dutrae Malme.: Detalhe do häbito. 


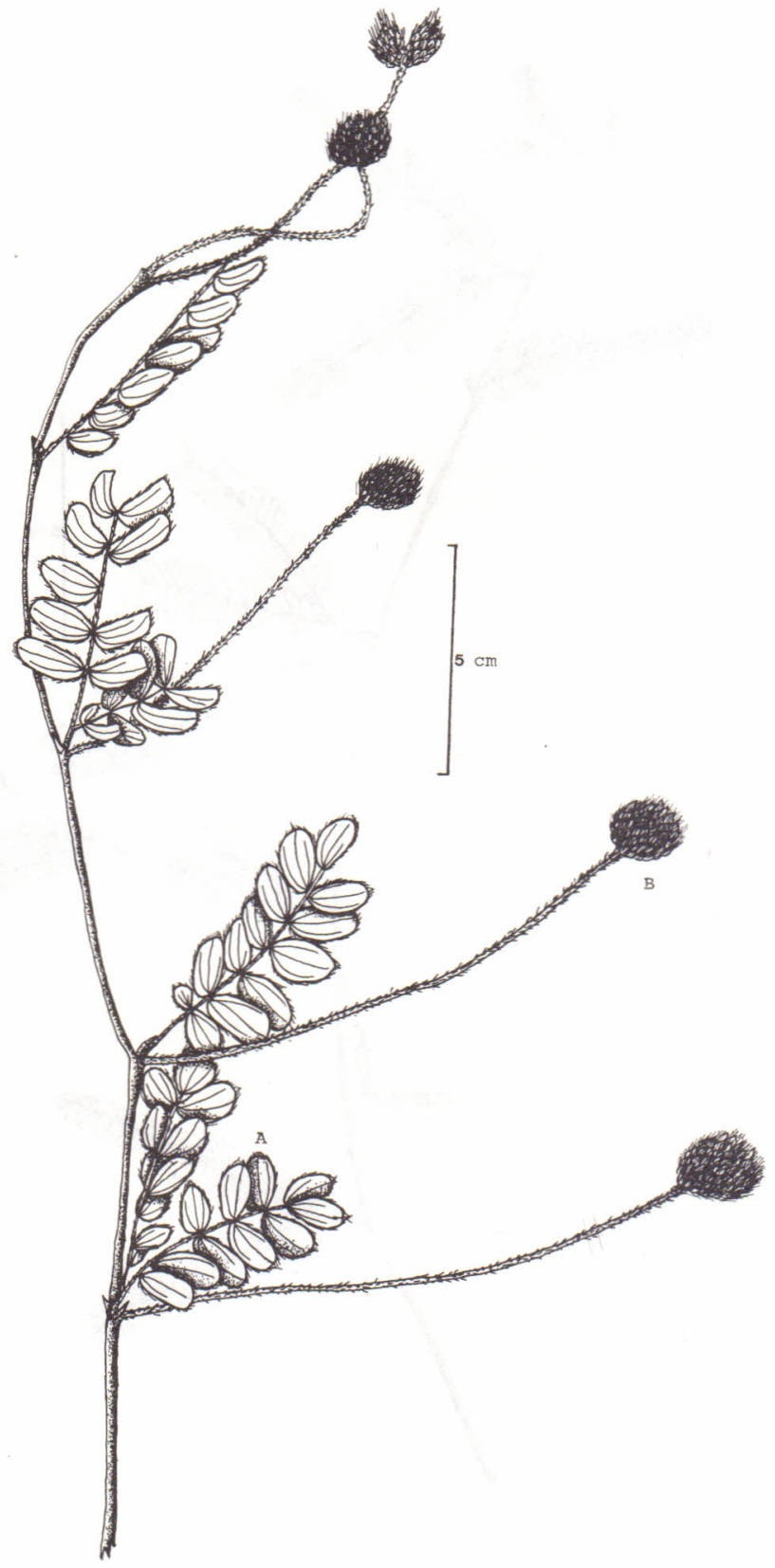

Figura 7 - Mimosa flagellaris Benth.: a) Detalhe do hábito

b) Inflorescência 
4. Prosopis algarobizza Griseb. (Algarrobo, espinilho, nhanduvā)

As espécies de Prosopis caracterizam-se pelo porte arbus tivo ou arbōreo, sendo resistentes à seca e bem adaptadas a solos de regiões āridas. Muitas destas espécies são agressivas, invadindo em certas äreas pastagens sub-tropicais, outras podem ser forrage $i$ ras valiosas em regiões com baixa precipitação e solos pobres. Por tanto, muitas espécies de Prosopis são potencialmente valiosas, em bora sejam exploradas de uma maneira bastante restrita.

o valor destas espécies para a alimentação do gado está nos seus frutos. A indeiscência dos legumes contribui para a conser vação de todas as substâncias nutritivas que, caso o fruto se abris se para permitir a liberação das sementes, se perderiam. As vagens são produzidas em grupos de 12 ou mais, medindo, usualmente, $20 \mathrm{~cm}$ de comprimento. Segundo publicação da NATIONAL ACADEMY OF SCIENCES (1979), a quantidade de mesocarpo numa vagem varia de ārvore para ärvore, constituindo, em algumas espécies, metade do peso do fruto. A quantidade de açūcar na polpa perfaz, frequentemente, $1 / 3$ do peso das vagens. De acordo com o trabalho mencionado acima, os frutos de Prosopis, no Havaī, Peru, Argentina e Chile, já sustentaram ani mais por um mês ou dois, quando não havia nenhuma outra espécie de alimento disponivel. Alëm disso, os frutos doces, muito bem aceitos pelos animais, possuem sementes ricas em proteỉnas (34-39\%,7-8\% de öleo), com alto valor nutritivo.

As espēcies de Prosopis tambēm produzem folhagens comestî veis, mas raramente isto se torna importante. Contudo, diversas gra mineas crescem muito bem quando consorciadas com estas ārvores. 0 nitrogēnio e sombreamento produzidos por estas espēcies, tornam-se evidentes na coloração e vigor das gramỉneas.

Quanto ao porte arbōreo, que poderia dificultar o alcance dos animais, PIMENTEL GOMES (1975), faz referência à prātica de cul tura herbācea de plantas arbōreas, utilizada no Japão, Cuba e Afri ca. As algarrobeiras, de acordo com o autor, poderiam ser plantadas a uma distāncia de $5 \mathrm{~m}$ umas das outras, cortadas com 1,50 m a 1,80 m de altura e assim mantidas. Por esta técnica, se formariam ramos la terais ao alcance dos herbivoros. Neste sistema, o algarrobal pode ria ser consorciado com outras forrageiras, gramineas ou legumino sas, herbāceas. Esta prātica consiste, portanto, em, atravēs de ar tifícios culturais, fazer com que plantas arbōreas forneçam cortes, como qualquer planta herbācea. O autor cita como exemplo desta prá tica, a utilização, na Asia, de Morus alba e Morus multicaulis. Es tas espēcies são semeadas ou plantadas em estacas muito prōximas $(0,5 \times 0,5 \mathrm{~m})$, sendo podadas, tornando possīvel atē a utilização de má quinas.

E importante frisar que algumas espēcies de Prosopis, 
sobretudo $P$. algarobizza, têm muita facilidade para rebrotar desde a base, quando cortadas. Deste modo, a utilização da técnica descri ta acima, não redundaria em prejuizo para a planta. Existe a crença de que os algarrobos possuem um desenvolvimento muito lento, mas o que deve ser frisado, é que existe uma variedade muito grande entre as espécies e, algumas delas, possuem crescimento rápido.

Quanto à germinação desta espēcie, BURKART (1940), deter minou que as sementes poderiam ser retiradas do endocarpo rasgando-se a testa do lado oposto ao hilo. De acordo com o autor, foi possivel observar, após duas semanas, o surgimento de uma primeira folha, pi nada com 7 a 8 pares de pỉnulas, depois dos cotilédones. A segunda folha surgida já era bipinada. As plantas alcançaram $20 \mathrm{~cm}$ de altu ra em 8 meses e não perderam as folhas no inverno. No segundo ano,o desenvolvimento foi räpido, atingindo $30 \mathrm{~cm}$. 0 autor observou, ain da, que os ramos tendiam a crescer horizontalmente. São descritos tambēm outros mētodos de germinação que obtiveram bons resultados, não sendo, contudo, especîficos para $P$. algarobizza, sendo interes sante testā-los tambēm com esta espēcie.

\section{CONCLUSÕES}

Tornou-se claro, quando da realização deste trabalho, a pe quena quantidade de informações a cerca das espēcies abordadas e o grande nümero de pontos a serem esclarecidos. Este fato é mais evi dente com relação à Cassia patelzaria DC. e Cassia rotundifolia Pers., apesar de possuirem inúmeros aspectos positivos e apesar das tenta tivas de exploração como cultura. No que diz respeito à Caesatpinia epunctata (Vog.) Benth., Cassia pilifera Vog., Cassia repens Vog. e espécies do gênero Mimosa, as informações são mais precārias. Des manthus depressus Humb. \& Bonpl. ex Willd. suscita dūvidas'quanto a sua distinção de D. virgatus (L.) Willd., sendo o hábito mais ereto e a menor ramificação desta, a característica vegetativa mais eviven te para diferenciar as espécies. Prosopis algarobizza Griseb., embo ra restrita a uma ārea pequena do nosso Estado, se utilizada como pasto arbóreo, poderia ser considerada uma boa forrageira, tornan do-se, desta maneira, mais uma opção para nossa agropecuária.

Embora estas espécies de MIMOSOIDEAE e CAESALPINIOIDEAE não possam ser consideradas ōtimas forrageiras, o estudo de suas ca racterísticas e comportamento sob pastejo deve ser encarado como de vital importância para o conhecimento e exploração racional de nos sas pastagens. Torna-se cada vez mais patente a necessidade destes estudos, para que programas de melhoramento e utilização sejam ela borados, visando um melhor aproveitamento dos recursos forrageiros do Estado. Através de trabalhos de caracterização botânica, determi nação de ciclos, comportamento quando da utilização pelos animais, 
conhecimento de variedades e melhoramento genético, algumas destas espécies, potencialmente mais promissoras, poderiam ser utilizadas no enriquecimento da qualidade dos campos naturais. Neste caso, se riam associadas a forrageiras de maior valor, talvez até com vanta gem, em relação ao material trazido de outras regiões, devido a sua maior adaptação às nossas condições.

\section{AGRADECIMENTOS}

A Professora Silvia Miotto, do Departamento de Botânica da Universidade Federal do Rio Grande do Sul, pela revisão, incenti vo e sugestões.

REFERENCIAS BIBLIOGRĀFICAS

ALCÁNTARA, P.B., BUfARAh, G. 1979. Plantas Forrageiras: gramineas e leguminosas. São Paulo, Nobel. $150 \mathrm{p}$.

ARAOJO, A.A. de. 1942. Forrageiras para o sul do Brasiz. Porto Ale gre, Secretaria de Estado dos Negōcios da Agricultura, Indústria e Comércio. $258 \mathrm{p}$.

BARRET0, I.L. \& KAPPEL, A. 1969. Principais espécies de graminneas e leguminosas das pastagens naturais do Rio Grande do Sul. In: CONGRESSO NACIONAL DE BOTÂNICA, 150,, Porto Alegre, 1969. Anais, Porto Alegre, Globo. p. 281.

BENTHAM, G. 1881. Leguminosae. I, II. In: MARTIUS, C.F.P. FZora bra siziensis. Monachit, R. Oldenburg.

BURKART, A. 1939. Descripciōn de Mimozyganthus, nuevo gēnero de le guminosa y sinopsis preliminar de los gēneros argentinos de Mimo soideae. Darwiniana, B. Aires, 3(3):445-469. - 1940. Materiales para una monografia del género Proso pis (1eg.). Damwiniana, B. Aires, 4(1):57-128. - 1952. Las leguminosas argentinas silvestris y cultivadas.

2 ed. B. Aires, Acme. 569 p. - 1979. Leguminosas: mimosoideas. Flora Ilustrada Catari nense, Itajai, LEGU. $304 \mathrm{p}$.

CABRERA, A. 1953. Manual de la flora de los alredores de Buenos A $\underline{i}$ res. B. Aires, Acme. $589 \mathrm{p}$. - 1965. Flora de la provincia de Buenos Aires. B. Aires, INTA. pt. 3, $671 \mathrm{p}$.

LEONARDIS, R.F.S. 1975. Livro del arbol: essencias florestales in digenas de la Argentina de aplicación industrial. B. Aires, Celu losa argentina. S.p.

MANGANARO, A. 1919. Leguminosas bonaerenses. Anales de la Soc. Cient. Arg., B. Aires, 87:77-264.

NATIONAL ACADEMY OF SCIENCES. 1979. Tropical legumes: resources for the future. Washington, National Academy of Sciences. $331 \mathrm{p}$. 
PARODI, L.P. 1959. Enciclopédia argentina de agricultura y jardine ria. B. Aires, Acme. $931 \mathrm{p}$.

PIMENTEL GOMES, R. 1975. Forragens fartas na seca. São Paulo, Nobel. $233 \mathrm{p}$.

RAMBO, B. Leguminosae riograndenses. 1966. Pesquisas, São Leopoldo (23).

ROCHA, G.L. da. 1971. Introdução e seleção de leguminosas forragej ras tropicais. In: SEMINARIO SOBRE METODOLOGIA E PLANEJAMENTO DE PESQUISA COM LEGUMINOSAS TROPICAIS, Rio de Janieiro, 1971. Anais, Rio de Janeiro, J. Döbereiner, P.A. da Eira, A.A. Franco e A. B. Campe10. p. 19-70.

ROCHA, G.L. da; LEITAO FILHO, H. de F.; ANDRADE, J.B.; SHEPHERD, E. J.; SEMIR, J.; GOUVEA, L.S.K.; GIBBS, P.E.; TAMASHIRO, J.; MONTEI RO, R.; ALCÂNTARA, P.B.; BUFARAH, G.; OLIVEIRA, P.R.P. de.; ALCĀN TARA, V.B.G.; ALMEIDA, J.E. de.; SALGADO, P.R.; PULZ, F.S.;SIGRST, J.M.M.; FONSECA, T.C.; PAULINO, V.T. 1979. Coleta, identificação e distribuição de leguminosas forrageiras tropicais brasileiraBrasil Central - Fase 1. B. Ind. Anim., Nova Odessa, 36(2):255-324.

Recebido em setembro, 1985; aceito em outubro, 1985. 